\title{
ANÁLISE DE CRESCIMENTO DE GIRASSOL EM SISTEMA DE SEMEADURA DIRETA
}

\author{
No Tillage Sunflower Growth Analysis
}

\author{
Denise Bruginski de Carvalho ${ }^{1}$
}

\section{Resumo}

Este trabalho foi conduzido no município de Palmeira, região dos Campos Gerais do Paraná, com o objetivo de analisar o crescimento de girassol cultivado em sistema de semeadura direta. O híbrido M 734 foi semeado em 24 de setembro e a adubação de base foi feita com aplicação de $300 \mathrm{~kg}$.ha-1 da fórmula 00-26-26. O solo utilizado foi caracterizado como argissolo vermelho-amarelo, textura média. Foi utilizado o delineamento completamente casualizado com cinco tratamentos equivalentes à época de análise e seis repetições. Nos estádios V8, V17, R1, R5.5 e R7 foram realizadas as seguintes avaliações: número de folhas, estatura da planta, diâmetro do caule, índice de área foliar (IAF), rendimento biológico (RB) e partição de massa seca. A análise de regressão das variáveis resultou em equações polinomiais de grau 3 significativas, $y=-$ $0,000081 \mathrm{x}^{3}+0,01 \mathrm{x}^{\prime \prime}+0,19 \mathrm{x}-4,5$ (número de folhas); $\mathrm{y}=-0,0011 \mathrm{x}^{3}+0,21 \mathrm{x}^{2}-10,22 \mathrm{x}+161,84$ (estatura da planta); $\mathrm{y}=-$ $0,00014 x^{3}+0,026 x^{2}-1,2 x+18,52$ (diâmetro do caule); $y=-0,0002 x^{3}+0,04 x^{2}-2,04 x+32,36$ (IAF); $y=-0,0023 x^{3}+0,49 x^{2}-$ $28,11 x+476,57(R B) ; y=-0,002 x^{3}+0,4 x^{2}-23,05 x+387,77$ (massa seca de folhas); $y=-0,000088 x^{3}+0,017 x^{2}-0,86 x+13,37$ (massa seca de pecíolo) e; $y=-0,00089 x^{3}+0,178 x^{2}-10,005 x+166,54$ (massa seca de caule). A estatura média máxima atingida pelas plantas de girassol foi $162 \mathrm{~cm}$. No estádio $\mathrm{R} 5.5$ foi registrada a maior média do índice de área foliar (15). No estádio R5.5 ocorreu o maior acúmulo de massa seca de pecíolo, caule e folhas. No estádio R7, em que se iniciava o período de enchimento de aquênios, foi registrado o maior valor médio de RB no período estudado.

Palavras-chave: Helianthus annuus L.; Morfologia da planta, IAF; Massa seca.

\section{Abstract}

This work was carried out in Palmeira, region of Campos Gerais, in Paraná. The objective was to make no tillage sunflower growth analysis. The hybrid M 734 was sowed in September with fertilizer 00-26-26, $300 \mathrm{~kg} \cdot \mathrm{ha}^{-1}$ in a red-yellow "argissol. It was used the completely random experimental design, with five treatments and six replications. The tested treatments were: V8, V17, R1, R5.5 e R7 stages to analyze the variables: leaves number, height of the plant, stem diameter, leaves area index (IAF), biological yield and dry matter separation. The regression analysis of variables resulted in significant cubic equations: $y=-0,000081 \mathrm{x}^{3}$ $+0,01 \mathrm{x}^{2}+0,19 \mathrm{x}-4,5$ (leaves number); $\mathrm{y}=-0,0011 \mathrm{x}^{3}+0,21 \mathrm{x} 2-10,22 \mathrm{x}+161,84$ (height of the plant); $\mathrm{y}=$ $-0,00014 x^{3}+0,026 x^{2}-1,2 x+18,52$ (stem diameter); $y=-0,0002 x^{3}+0,04 x^{2}-2,04 x+32,36$ (LAI); $y=-0,0023 x^{3}+0,49 x^{2}-$ $28,11 x+476,57$ (biological yield); $y=-0,002 x^{3}+0,4 x^{2}-23,05 x+387,77$ (dry matter of leaves); $y=-0,000088 x^{3}$ $+0,017 x^{2}-0,86 x+13,37$ (dry matter of petiole) and; $y=-0,00089 x^{3}+0,178 x^{2}-10,005 x+166,54$ (dry matter of stem). The largest average height achieved by the sunflower plants was $162 \mathrm{~cm}$. The largest average for IAF (15) was registered in the R5.5 stage. In the R5.5 stage was reached the highest petiole, stem and leaves dry matter accumulation. In addition, in the R7 stage, when the fitting of the achenes began, was registered the highest average of biological yield during studied period.

Keywords: Helianthus annuus L.; Plant morphology; IAF; Dry matter.

1 Engenheira Agrônoma, CREA-PR 28300-D, MSc., aluna de doutorado do Curso de Pós-graduação em Agronomia - Produção Vegetal, UFPR, bolsista da CAPES. Rua dos Funcionários, 1540, Curitiba/PR, CEP 80035-050. denisehb@agrarias.ufpr.br 


\section{Introdução}

O cultivo do girassol pode representar uma boa alternativa para rotação de culturas em áreas destinadas ao cultivo de grãos. O girassol pode ser produzido com diferentes finalidades, podendo-se considerar como principais a produção de grãos para extração de óleo e a produção de massa seca para alimentação animal, na forma de silagem. As qualidades do óleo de girassol, tais como a quantidade de óleos essenciais e as características organolépticas, determinam a boa demanda de mercado.

Estudos recentes relatam a importância da adubação e relações hídricas para o bom desenvolvimento e produção do girassol (CASTRO et al., 1999; LOPEZ BELLIDO et al., 2000; TORELLA et al., 2001). O girassol responde à maior disponibilidade de nitrogênio no solo, aumentando a área foliar (MUNDSTOCK; ZAGONEL, 1994). A taxa de crescimento do girassol está associada positivamente com a temperatura e é muito sensível às oscilações hídricas do solo (BARNI et al., 1995).

$O$ índice de área foliar pode ser usado para relacionar a arquitetura e produtividade da planta. A posição das folhas determina o aproveitamento da luz numa determinada população, afetando a taxa de fotossíntese (SALISBURY; ROSS, 1992).

O rendimento biológico da cultura, representado pelo acúmulo total de massa seca, pode ser alterado por fatores edafoclimáticos e culturais. A época de semeadura do girassol pode alterar a distribuição e acúmulo de matéria seca (SANGOI; SILVA, 1988).

O objetivo deste trabalho foi analisar o crescimento do girassol cultivado em sistema de semeadura direta.

\section{Materiais e métodos}

O experimento foi conduzido em um solo caracterizado como argissolo vermelho-amarelo, textura média, (EMBRAPA/CNPS, 1999), no município de Palmeira, região dos Campos Gerais do Paraná, localizado entre as coordenadas de $25^{\circ} 21^{\prime}$ de latitude Sul e $49^{\circ}$ 56' de longitude Oeste e altitude de 820 m (FUNDAÇÃO INSTITUTO AGRONÔMICO DO PARANÁ, 1984). As características químicas do solo são apresentadas na Tabela 1.

\section{TABELA 1 - Caracterização química do solo da área experimental, Palmeira, PR. ${ }^{1}$}

Table 1 - Soil chemical characterization of the experimental area, Palmeira, PR ${ }^{1}$

\begin{tabular}{lrccccrrr}
\hline \multirow{2}{*}{$\begin{array}{l}\text { Profundidade } \\
(\mathrm{cm})\end{array}$} & $\begin{array}{r}\mathrm{pH} \\
\left(\mathrm{CaCl}_{2}\right)\end{array}$ & $\mathrm{Al}^{+3}$ & $\mathrm{H}+\mathrm{Al} \quad \mathrm{Ca}^{+2}+\mathrm{Mg}^{+2}$ & $\mathrm{~K}^{+}$ & $\begin{array}{r}\mathrm{P} \\
\left(\mathrm{cmol}_{\mathbf{c}} \cdot \mathrm{dm}^{-3}\right)\end{array}$ & $\begin{array}{r}\text { Matéria } \\
\text { orgânica }\end{array}$ & $\begin{array}{r}\text { Saturação } \\
\text { por bases }\end{array}$ \\
\hline $00-10$ & 4,4 & 0,3 & 5,8 & 4,2 & 0,2 & 6,0 & 33 & 43,1 \\
$10-20$ & 4,2 & 0,5 & 6,2 & 3,0 & 0,1 & 1,0 & 30 & 33,5 \\
$20-40$ & 4,0 & 0,7 & 6,7 & 2,8 & 0,1 & 1,0 & 21 & 30,3 \\
\hline
\end{tabular}

Análises realizadas no Laboratório de Análises de Solos do Departamento de Solos da UFPR.

O cultivo do girassol foi feito em sistema de semeadura direta sobre cobertura morta formada pelo cultivo da aveia-preta (Avena strigosa) dessecada (aplicação de 960 g.ha-1 de glyphosate, misturado com 0,5 L.ha ${ }^{-1}$ de óleo mineral), uma semana antes da semeadura.

A semeadura foi realizada em setembro, utilizando-se o híbrido M 734 que é recomendado para o estado do Paraná (EMBRAPA/CNPSo,
1997). Este híbrido apresenta ciclo tardio, maturação fisiológica aos 103 dias após a emergência e teor de óleo nos aquênios de aproximadamente 41\% (ROSSI, 1998). A adubação de base foi feita com aplicação de $300 \mathrm{~kg}$.ha ${ }^{-1}$ da fórmula 0026-26, seguindo a recomendação para semeadura convencional (CASTRO et al., 1997; TOMÉ, 1997) com base nos resultados da análise química do solo. 
Foi realizada a semeadura mecanizada distribuindo-se cinco sementes por metro de sulco e mantendo-se $0,9 \mathrm{~m}$ entre linhas, visando ao estabelecimento de uma população de 50 mil plantas ha $^{-1}$ (CASTRO et al., 1997).

Em cada parcela, nos estádios descritos na Tabela 2, foram amostradas vinte plantas, cortadas rente ao solo para as avaliações das seguintes variáveis: a) número de folhas por planta; b) estatura da planta, medida do nível do solo até a altura do meristema apical; c) diâmetro do caule, à altura de $5 \mathrm{~cm}$ do solo; d) índice de área foliar, calculado por meio da fórmula: $\mathrm{IAF}=[(\mathrm{AF}) \mathrm{X}(\mathrm{P})] / 10000$, em que: $\mathrm{IAF}=$ índice de área foliar, $\mathrm{AF}=$ área foliar $\left(\mathrm{cm}^{2}\right)$, medida por meio de aparelho integrador de área foliar "Automatic Area Meter", modelo AAC 400, P= número de plantas. $\mathrm{m}^{-2}$; e) rendimento biológico, representado pela massa seca total da planta desprezando-se o sistema radicular e, partição de massa seca em massa seca de caule, pecíolo e folha, obtida após secagem em estufa com circulação forçada de ar e mantida à temperatura de $75^{\circ} \mathrm{C}$ até peso constante.

\section{TABELA 2 - Estádios fenológicos do girassol ${ }^{1} \mathrm{em}$ que foram realizadas as avaliações e 0 tempo transcorrido entre a emergência e a avaliação.}

Table 2 - Phonological stages of girassol ${ }^{1}$ where the evaluations and the elapsed time between the emergency and the evaluation had been carried through.

\section{Estádios}

Descrição Dias após a emergência

\begin{tabular}{lrr}
\hline V8 & planta com 8 folhas com mais de $4 \mathrm{~cm}$ & 30 \\
V17 & planta com 17 folhas com mais de $4 \mathrm{~cm}$ & 45 \\
R1 & aparecimento do broto floral & 60 \\
R5.5 & floração plena & 90 \\
R7 & primeira fase do desenvolvimento de aquênios & 105 \\
\hline
\end{tabular}

\footnotetext{
${ }^{1}$ Segundo a escala proposta por Schneiter e Miller (1981).
}

O delineamento experimental utilizado foi o de blocos ao acaso, com cinco tratamentos equivalentes às épocas de avaliação e seis repetições. Os resultados das avaliações foram submetidos à análise de regressão para verificação das tendências de crescimento das plantas no período estudado.

\section{Resultados}

Os dados de temperatura e pluviosidade registrados no período de realização do experimento foram relacionados com as fases de desenvolvimento do girassol (TABELA 3). 


\section{TABELA 3 - Temperatura e precipitação pluviométrica no período estudado (24 de setembro a 18 de fevereiro), relacionadas com as fases de desenvolvimento do girassol.}

Table 3 - Temperature and precipitation in the studied period (between September 24 and February 18), related with the sunflower development phases.

\begin{tabular}{lrrrrr}
\hline Fases & $\begin{array}{r}\text { Duração } \\
\text { de }\end{array}$ & $\begin{array}{r}\text { Precipitação } \\
(\mathrm{mm})\end{array}$ & $\begin{array}{r}\text { Temperatura } \\
\text { máxima }\end{array}$ & $\begin{array}{r}\text { Temperatura } \\
\text { mínima }\end{array}$ & $\begin{array}{r}\text { Temperatura } \\
\text { média } \\
\text { desenvolvimento }\end{array}$ \\
\hline Emergência & 11 & 162,2 & 26,8 & 7,6 & 17,4 \\
Crescimento & 85 & 269,4 & 33,0 & 11,1 & 19,2 \\
Florescimento & 20 & 108,6 & 28,6 & 12,9 & 20,2 \\
\hline
\end{tabular}

Fonte: Sistema Meteorológico do Paraná.

A precipitação pluviométrica desde a semeadura até a colheita foi de $664,4 \mathrm{~mm}$, suficiente para o bom desenvolvimento do girassol que requer 500 a $700 \mathrm{~mm}$ de água durante seu ciclo (CASTRO et al., 1997).

A faixa de temperatura entre 10 a $24^{\circ} \mathrm{C}$ é tolerada pelo girassol sem redução significativa da produção. As plantas podem suportar temperaturas baixas por curto período, principalmente nos estádios iniciais (CASTRO et al., 1997), por este motivo a temperatura mínima de $7,6^{\circ} \mathrm{C}$, registrada no período de germinação, não deve ser considerada como limitante.

A temperatura ótima para o seu desenvolvimento situa-se na faixa entre 27 a $28^{\circ} \mathrm{C}$, conforme menciona Castro etal. (1997), mas nas condições climáticas de realização do experimento, a média de temperatura foi de $20,1^{\circ} \mathrm{C}$ aumentando a duração do ciclo do girassol.

O período entre a germinação e a emergência foi prolongado de 7 dias, período normal considerado por Castiglioni et al., (1997) para 11 dias após a semeadura devido à temperatura média do período ser inferior à temperatura ótima de $20^{\circ} \mathrm{C}$.

O período de crescimento vegetativo, com duração de 85 dias, também foi prolongado, considerado ideal por Castiglioni et al.
(1997), entre 45 a 70 dias. A temperatura média de $19,2^{\circ} \mathrm{C}$, abaixo da faixa ideal de 25 a $27^{\circ} \mathrm{C}$ ocasionou o prolongamento desta fase. Segundo Castiglioni et al. (1997), o consumo de água requerido na fase de crescimento é de 1,8 a $6,2 \mathrm{~mm}$ por dia, sendo que nas condições do experimento houve precipitação média diária de $3,1 \mathrm{~mm}$.

Durante a fase de florescimento, a temperatura máxima registrada foi de $28,6^{\circ} \mathrm{C}$, abaixo do limite de $35^{\circ} \mathrm{C}$. Temperaturas elevadas aceleram o florescimento e dificultam a polinização adequada (CASTIGLIONI et al., 1997). No período de florescimento, que ocorreu em 20 dias, a precipitação média diária foi de $5,4 \mathrm{~mm}$, valor abaixo do requerido, que é de 6 a $8 \mathrm{~mm}$ (CASTIGLIONI et al., 1997).

As primeiras oito folhas das plantas apresentaram filotaxia oposta e as demais filotaxia espiral, havendo uma boa distribuição espacial devido ao espaçamento e população utilizados. O número total de folhas variou pouco, sendo que as plantas apresentaram em média trinta e oito folhas expandidas em pleno florescimento, em seguida iniciando a deterioração das mais velhas. A análise da quantidade de folhas nas plantas resultou numa equação polinomial de $3^{\circ}$ grau, representada no Gráfico 1. 


\section{GRÁFICO 1 - Número de folhas de girassol cultivado em sistema de semeadura direta em cinco estádios de desenvolvimento.}

Graph 1 - Leaf number of sunflower cultivated in direct sowing system in five development stages.

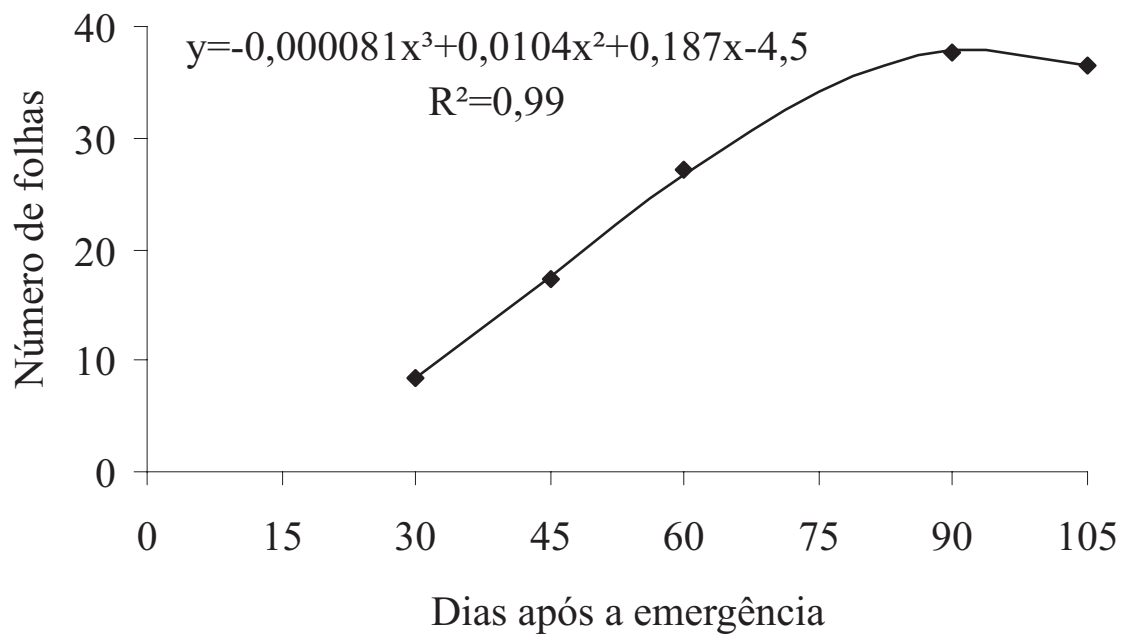

A altura média máxima atingida pelas plantas de girassol foi $162 \mathrm{~cm}$. O crescimento inicial foi lento, sendo que a maior altura foi registrada em pleno florescimento, como já descrito anteriormente (CASTRO et al., 1997).
Por meio de regressão linear propôs-se uma equação cúbica para representar a tendência dos dados de crescimento em altura das plantas de girassol, tendo resultado em bom ajuste (GRÁFICO 2).

\section{GRÁFICO 2 - Altura das plantas de girassol cultivado em sistema de semeadura direta em cinco estádios de desenvolvimento.}

Graph 2 - Height of sunflower plants cultivated in direct sowing system in five development stages.

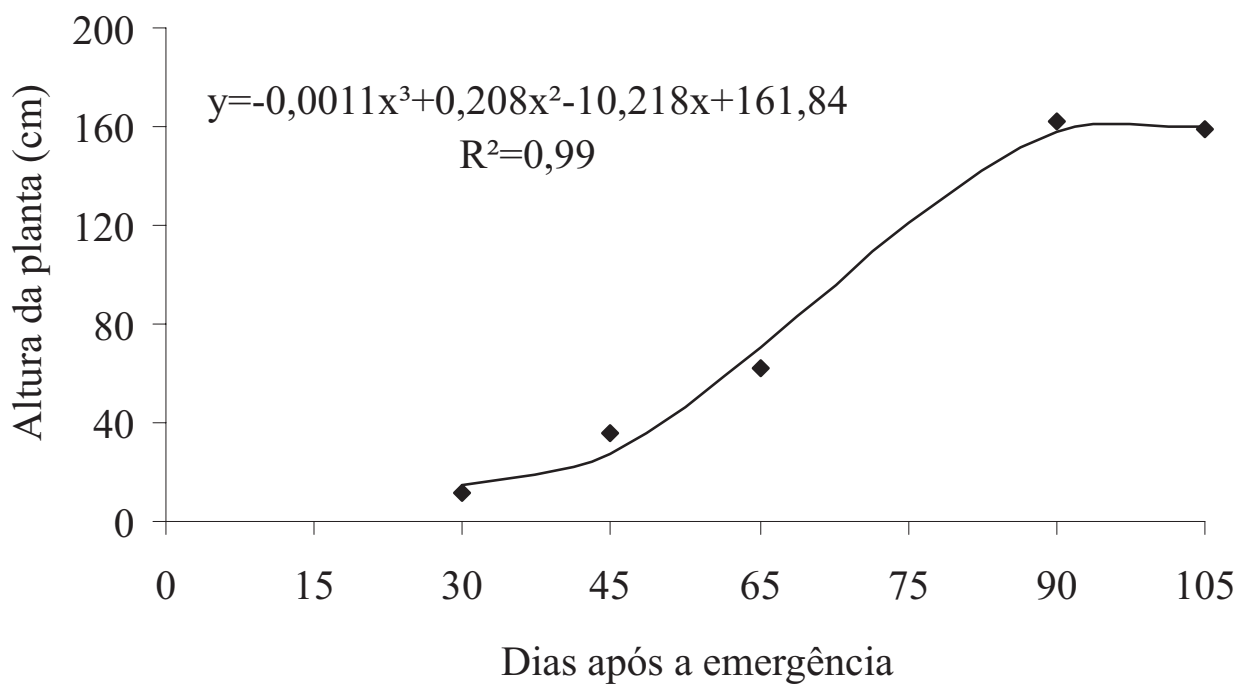

Ajustou-se uma equação cúbica aos dados referentes ao diâmetro do caule, por meio de regressão linear, obtendo-se bom resultado, representada no Gráfico 3. 


\section{GRÁFICO 3 - Diâmetro do caule de plantas de girassol cultivado em sistema de semeadura direta em cinco estádios de desenvolvimento.}

Graph 3 - Stem diameter of sunflower plants aultivated in direct sowing system in five development stages.

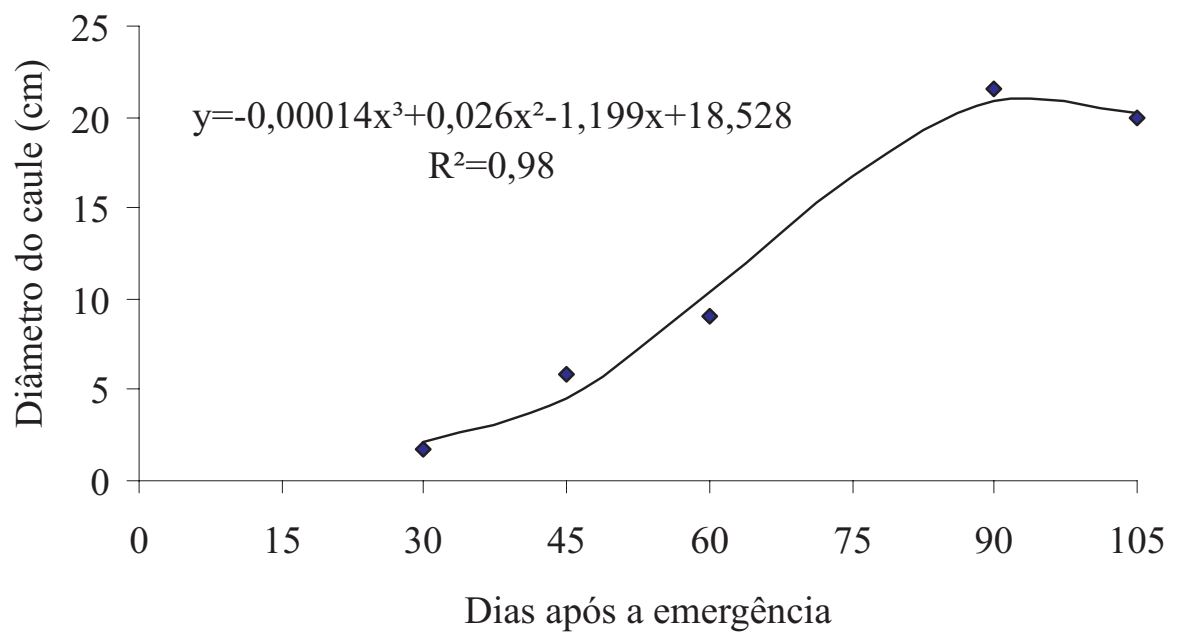

A curva obtida é semelhante à curva representativa da altura das plantas, sendo o maior diâmetro médio obtido de $21 \mathrm{~mm}$. O percentual de plantas acamadas e quebradas em todo experimento foi de $1,7 \%$ e $0,4 \%$, respectivamente, o que pode ser considerado normal pela altura das plantas.

O índice de área foliar médio mais elevado foi alcançado nas condições deste experimento no estádio R5.5 (IAF $=15$ ). Salisbury e Ross (1992) consideram comum índices maiores que 12 em populações de espécies arbóreas. No caso do cultivo do girassol, o IAF mais elevado ocorre no período de florescimento pleno, relevante para a produção de fotoassimilados, boa produtividade de grãos ou para produção de massa seca para silagem. A área foliar abundante ocorreu provavelmente devido ao alto teor de matéria orgânica na camada superficial do solo (TABELA 1). Como fonte de N, a matéria orgânica esteve disponível desde os primeiros estádios de desenvolvimento da planta, resultando em aumento da área foliar. Esta afirmativa está de acordo com os resultados encontrados por Mundstock e Zagonel (1994), que concluíram que o girassol responde à maior disponibilidade de nitrogênio no solo, aumentando área foliar.

A análise estatística dos dados obtidos para o IAF resultou numa equação cúbica, apresentada no Gráfico 4.

\section{GRÁFICO 4 - Índice de área foliar de girassol cultivado em sistema de semeadura direta em cinco estádios de desenvolvimento.}

Graph 4 - Leaf area index of sunflower cultivated in direct sowing system in five development stages.

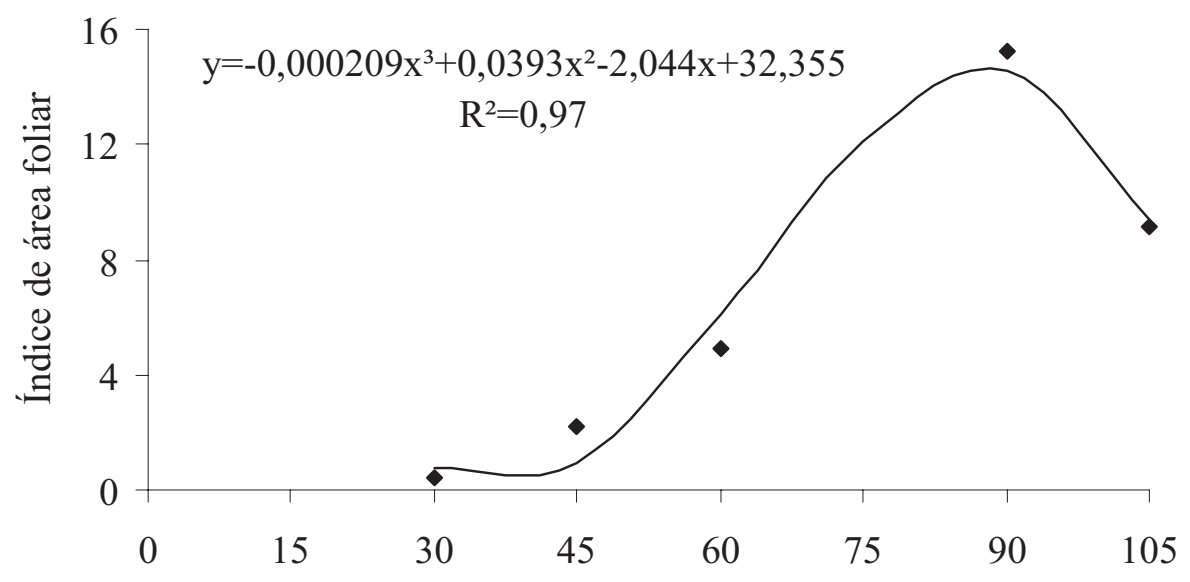

Dias após a emergência 
A análise dos dados obtidos para massa seca resultou nas seguintes equações: $y=-0,0023 x^{3}+0,49 x^{2}-28,11 x+476,57 ; R^{2}=$ 0,97 (massa seca total ou RB); $y=-0,002 x^{3}+0,4 x^{2}-23,05 x+387,77 ; R^{2}=0,95$ (massa seca de folhas);

\section{GRÁFICO 5 - Massa seca total (RB) de folha, caule e pecíolo de girassol cultivado em sistema de semeadura direta em cinco estádios de desenvolvimento. Graph 5 - Leaf, stem and petiole total dry mass (RB) of sunflower cultivated in direct sowing system in five development stages.}

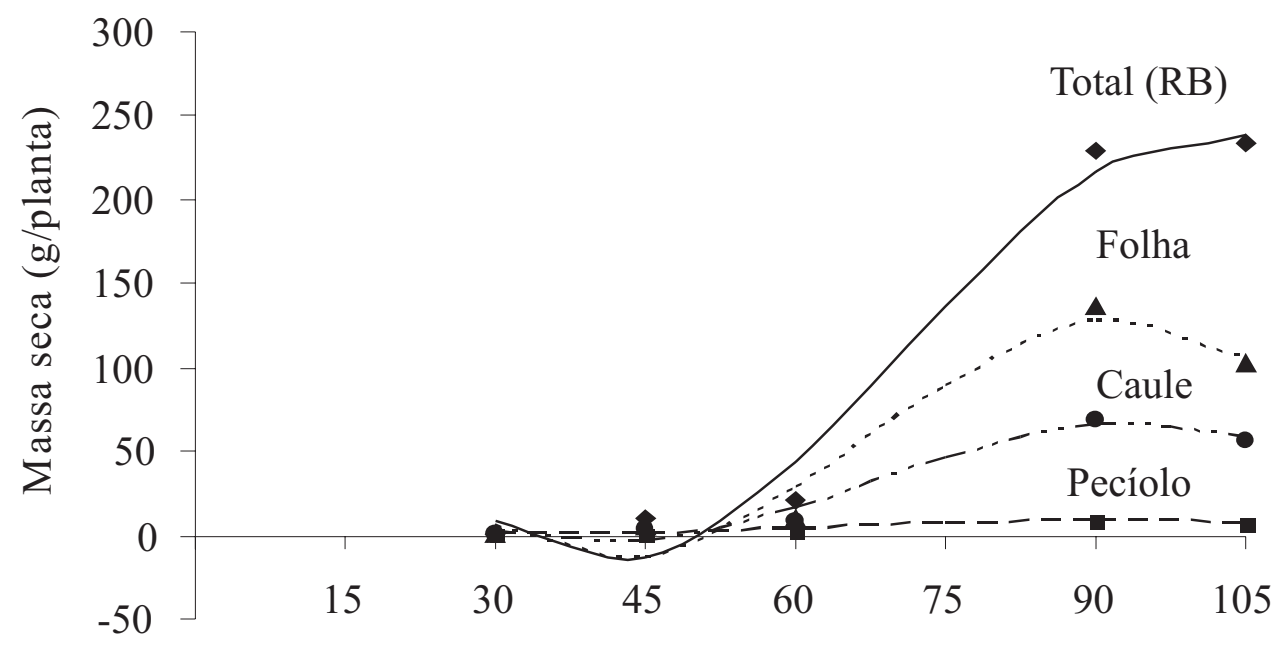

Dias após a emergência

A distribuição de massa seca nas plantas aumentou proporcionalmente nos estádios V17, R1 e R5.5, sendo esse último o pico dos maiores valores atingidos para massa seca de pecíolo, caule e folhas, porém não o maior para o RB. No estádio $\mathrm{R} 7$, em que se iniciava o período de enchimento de aquênios, foi registrado o maior valor médio de RB. Segundo Nichiporovich (1960), citado por Barni et al., (1995), o rendimento biológico pode ser associado ao índice de colheita para analisar a eficiência da partição dos produtos fotossintetizados. Neste caso, a relação entre o rendimento biológico e a produtividade média encontrada (2053 $\left.\mathrm{kg} \cdot \mathrm{ha}^{-1}\right)$ não se afigura conclusiva, concernente à eficiência fotossintética das plantas, mas pode-se considerar que o RB médio no estádio R7 (238 g/ planta) esteja associado ao bom estado nutricional das plantas e as condições climáticas razoáveis.

\section{Considerações finais}

As condições edafoclimáticas e de manejo, nas quais o girassol se desenvolveu no presente estudo, proporcionaram um bom desenvolvimento das plantas, que atingiram a altura média de 1,62m, com diâmetros do caule de $2,1 \mathrm{~cm}$ e o índice de área foliar médio mais elevado foi alcançado, nas condições deste experimento, no estádio R5.5 (IAF = 15) e RB de $238 \mathrm{~g} /$ planta.

As curvas de crescimento representadas a partir de equações cúbicas ajustadas para todas as variáveis estudadas não são adequadas para extrapolação de dados. Desta forma, as interpretações realizadas restringem-se somente à interpolação de dados para o período considerado neste estudo. 


\section{Referências}

BARNI, N. A. et al. Análise de crescimento do girassol em resposta a cultivares, níveis de adubação e épocas de semeadura. Pesquisa Agropecuária Gaúcha, Porto Alegre, v. 1, n. 2, p. 167-184. 1995.

CASTIGLIONI, V. B. R. et al. Fases de desenvolvimento daplantade girassol. Londrina: EMBRAPACNPSo, 1994. p. 24. (Documentos, 58).

CASTRO, C. et al. Doses e métodos de aplicação de nitrogênio em girassol. Scientia Agricola, v. 56, n. 4, p. 827-833. 1999.

CASTRO, C. et al. A Cultura do girassol. Londrina: EMBRAPA-CNPSo, 1997. p. 36.(Circular Técnica, 13)

EMBRAPA/CNPS. Sistema Brasileiro de Classificação de Solos. Rio de Janeiro: RJ, EMBRAPA. Solos, 1999. p. 412.

EMBRAPA/CNPSO. Informes da avaliação de genótipos de girassol, 1996/97 e 1997. Londrina, 1997. p. 116. (EMBRAPA - CNPSo. Documentos, 110)

FUNDAÇÃO INSTITUTO AGRONÔMICO DO PARANÁ. Cartas climáticas do Estado do Paraná. Londrina, 1984. p. 45.
LOPEZ BELLIDO, L. et al. Effects of tillage, crop rotation, and nitrogen fertilization on wheat under rainfed Mediterranean conditions. Agronomy Journal, v. 92, n. 6, p. 1054-1063. 2000.

MUNDSTOCK, C. M.; ZAGONEL, J. Perfil de área foliar de duas cultivares de girassol sob doses e épocas de aplicação de nitrogênio em cobertura. Pesquisa Agropecuária Brasileira, v. 29, n. 6, p. 847-851. 1994.

ROSSI, R. O. Girassol. Curitiba: Tecnoagro, 1998. p. 333.

SALISBURY, F. B.; ROSS C. W. Plant physiology. Califórnia: Wadsworth, 1992. p. 682.

SANGOI, L.; SILVA, P. R. F. da. Distribuição e acúmulo de matéria seca em duas cultivares de girassol em três épocas de semeadura. Pesquisa Agropecuária Brasileira. Brasília, v. 23, n. 5, p. 489-502, 1988.

TOMÉ, J. B. Jr. Manual para interpretação de análise de solo. Guaíba: Agropecuária, 1997. p. 247.

TORELLA, J. L. et al. Tillage, liming and sunflower. Agrochimica, v. 45, n. 1-2, p. 14-23, 2001.

Recebido: 07/12/2003 Aprovado: 30/06/2004 